\section{Structure of Biogenic Uraninite Produced by Shewanella oneidensis Strain MR-1}

\author{
ELEANOR J. SCHOFIELD, *, \\ HARISH VEERAMANI, \\ JONATHAN O. SHARP, \\ ELENA SUVOROVA, \\ RIZLAN BERNIER-LATMANI, \\ APURVA MEHTA, ${ }^{\dagger}$ \\ JONATHAN STAHLMAN, ${ }^{\dagger}$ \\ SAMUEL M . WEBB, ${ }^{\dagger}$ DAVID L. CLARK, \\ STEVEN D. CONRADSON,"

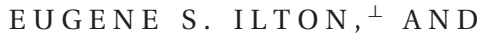 \\ J OH R . B A R A R ${ }^{\dagger}$ \\ Stanford Synchrotron Radiation Laboratory, 2575 Sand Hill \\ Rd., Menlo Park, California 94025, Environmental, \\ Microbiology Laboratory, École Polytechnique Fédérale de \\ Lausanne, Lausanne, CH 1015, Switzerland, Seaborg Institute \\ for Transactinium Science, ADSMS, MS-G756, Los Alamos \\ National Laboratory, Los Alamos, New Mexico 87545, Los \\ Alamos National Laboratory, Los Alamos, New Mexico 87545, \\ Pacific Northwest National Laboratory, PO Box 999, MSIN: \\ K8-96, Richland, Washington 99352, and Environmental \\ Science and Engineering, Colorado School of Mines, Golden, \\ Colorado 80401-1887
}

Received February 26, 2008. Revised manuscript received June 18, 2008. Accepted June 18, 2008.

The stability of biogenic uraninite with respect to oxidation is seminal to the success of in situ bioreduction strategies for remediation of subsurface $\mathrm{U}(\mathrm{VI})$ contamination. The properties and hence stability of uraninite are dependent on its size, structure, and composition. In this study, the local-, intermediate-, and long-range molecular-scale structure of nanoscale uraninite produced by Shewanella oneidensis strain MR-1 was investigated using EXAFS, SR-based powder diffraction and TEM. The uraninite products were found to be structurally homologous with stoichiometric $\mathrm{UO}_{2}$ under all conditions considered. Significantly, there was no evidence for lattice strain of the biogenic uraninite nanoparticles. The fresh nanoparticles were found to exhibit a well-ordered interior core of diameter ca. $1.3 \mathrm{~nm}$ and an outer region of thickness ca $\sim 0.6 \mathrm{~nm}$ in which the structure is locally distorted. The lack of nanoparticle strain and structural homology with stoichiometric $\mathrm{UO}_{2}$ suggests that established thermodynamic parameters for the latter material are an appropriate starting point to model the behavior of nanobiogenic uraninite. The detailed structural analysis in this study provides an essential foundation for subsequent investigations of environmental samples.

\footnotetext{
* Corresponding author phone: 650-926-2098; fax: 650-926-4100; e-mail: eleanors@slac.stanford.edu.

† Stanford Synchrotron Radiation Laboratory.

‡ École Polytechnique Fédérale de Lausanne.

* Colorado School of Mines.

$\$$ Seaborg Institute for Transactinium Science.

"Los Alamos National Laboratory.

${ }^{\perp}$ Pacific Northwest National Laboratory.
}

\section{Introduction}

Uranium in its oxidized form $(\mathrm{U}(\mathrm{VI}))$, is one of the most common, abundant, and problematic subsurface contaminants at legacy nuclear sites (1-3). Stimulated bioreduction of shallow U(VI) contaminated aquifers to U(IV) has been proposed as a means to immobilize $U$ (4-9) and form uraninite $\left(\mathrm{UO}_{2}\right)$ which has low solubility relative to $\mathrm{U}(\mathrm{VI})$. A seminal issue regarding the success of this strategy is the stability of this material with respect to oxidation and dissolution in the subsurface, which in turn depends upon its size, structure, and composition and their contribution toward its thermodynamic identity. Biogenic uraninite (nominal formula $\mathrm{UO}_{2}$ ) has been reported to be nanoparticulate with a typical particle size of $<3 \mathrm{~nm}$ and to exhibit a strained lattice (as inferred from the $3.85 \AA \mathrm{U}-\mathrm{U}$ shell distance), suggesting it would have significantly elevated solubility (10). In opposition to this conclusion, natural uraninite analogs ubiquitously incorporate foreign cation impurities, are hyperstoichiometric (containing excess $\mathrm{O}$ and/ or $\mathrm{U}(\mathrm{VI})$ ) and are stable under conditions where pure stoichiometric $\mathrm{UO}_{2.00}$ corrodes (11-13). A detailed structural analysis of biogenic uraninite, including lattice strain and intermediate-range $\mathrm{U}-\mathrm{U}$ correlations, has not been performed using direct probes. We report the detailed structure of nanobiogenic uraninite produced by Shewanella oneidensis MR-1 in the absence of dissolved impurity cations. The goal of this investigation is to provide a robust and accurate structural chemical model for nanobiogenic uraninite to enhance our understanding of the factors that control its chemical stability and to provide a foundation for forthcoming studies of environmentally relevant (compositionally complex and aged) samples.

Suzuki et al. reported that biogenic uraninite produced by sediment microbes and Desulfosporosinus spp., had a significantly contracted local structure, as defined by a $\sim 3.80$ $\AA \mathrm{U}-\mathrm{U}$ peak (10), the shortest $\mathrm{U}-\mathrm{U}$ interatomic distance in the $\mathrm{UO}_{2}$ structure, compared to $3.87 \AA$ as expected from XRD (14). Other studies, including the present paper, also report contracted $\mathrm{U}-\mathrm{U}$ distances in biogenic uraninites (15-17). These diminished $\mathrm{U}-\mathrm{U}$ distances in biogenic uraninite generally have been attributed to contraction of the uraninite lattice resulting from compressive strain of the nanoparticles $(10,15)$. This paper demonstrates that the uraninite lattice is unstrained and that short-range structure obtained from EXAFS can not be equated to long-range structure (unit cell dimensions). Senko et al. (15) presented evidence that slower $\mathrm{U}(\mathrm{VI})$ reduction rates lead to slightly larger particle diameter and slower reoxidation. Recent work has shown that microbially reduced U(VI) may occur as absorbed complexes on biomass and mineral surfaces, or as phosphate complexes $(6,18)$, which may interfere with EXAFS analyses of biogenic uraninite. Thus, unequivocal structural characterization of biogenic uraninite is greatly facilitated by the separation of the biooxides from biomass as performed here and elsewhere (16).

The present paper builds upon these previous studies by integrating low-temperature extended X-ray absorption fine structure (EXAFS) spectroscopy with in situ synchrotron powder-diffraction (SR-PD) to quantify the local-, intermediate-, and long-range structure of biogenic uraninite. Pure fresh uraninite is investigated here as a necessary prelude to understanding more complicated environmental biogenic uraninite. Published on Web 09/25/2008 
TABLE 1. Biogenic Samples

$\begin{array}{cll}\text { sample } & \mathbf{p H} & \text { cleaning technique } \\ \text { A } & 8 & \text { none } \\ \mathrm{B} & 8 & 1 \mathrm{M} \mathrm{NaOH} \\ \mathrm{C} & 8 & \text { Iysozyme } \\ \mathrm{D} & 6.3 & \text { none } \\ \text { E } & 6.3 & 1 \mathrm{M} \mathrm{NaOH} \\ \text { F } & 6.3 & \text { Iysozyme }\end{array}$

\section{Materials and Methods}

Sample Preparation. Fresh biogenic uraninite samples were prepared at École Polytechnique Fédérale de Lausanne (EPFL), Switzerland as described in the Supporting Information (SI) section and are summarized in Table 1. Shewanella oneidensis strain MR-1 was chosen for U(VI) reduction as it has been studied extensively $(19,20)$, and it is representative of U(VI)-reducing Shewanella spp. observed in the subsurface (21). Samples were prepared at $\mathrm{pH} 8$ or 6.3 . The variance of $\mathrm{pH}$ was of importance for future studies where the process will be carried out in the presence of groundwater cations in an attempt to incorporate them in to the $\mathrm{UO}_{2}$ structure. Synthetic $\mathrm{UO}_{2.00}$ and $\mathrm{UO}_{2+x}$ was prepared at Los Alamos National Laboratory as described in the SI section.

Transmission Electron Microscope (TEM) Analysis. TEM analysis was completed at EPFL. Samples were dried on a copper grid/carbon film in an anaerobic environment. The morphology, size, and structure of the particles were studied in a FEI CM300UT FEG (300 kV field emission gun, $0.65 \mathrm{~nm}$ spherical aberration, and $0.17 \mathrm{~nm}$ resolution at Scherzer defocus) by conventional transmission electron microscopy (TEM), high resolution transmission electron microscopy (HRTEM) and transmission electron diffraction (TED). The images were recorded on a Gatan 797 slow scan CCD camera with a $1024 \times 1024$ pixels / 14 bit detector and processed with the Gatan Digital Micrograph 3.11.0 software. The interpretation of HRTEM images, selected area electron diffraction (SAED) patterns and diffractograms (Fourier transforms of HRTEM images) was performed with the JEMS software package (22). The size of the nanoparticles was estimated using Fourier filtered HRTEM images by applying different masks for improved viewing of particle edges. Low-dose illumination conditions were used to record the images in order to prevent sintering of particles under the electron beam.

X-ray Absorption Spectroscopy Data Collection and Analysis. All sample manipulation at SSRL was carried out under an anaerobic atmosphere (5\% hydrogen, balance nitrogen). Centrifuged wet samples were loaded in Al sample holders with Kapton windows. Samples were stored wet and anaerobic until analysis. U $\mathrm{L}_{\mathrm{III}}$-edge transmission spectra were collected at SSRL beamlines 11-2 and 10-2, using a Si (220) double-crystal monochromator. The beam profile was defined as $1 \mathrm{~mm}$ vertical by $1 \mathrm{~mm}$ horizontal for the biogenic samples and $1 \mathrm{~mm}$ vertical by $3 \mathrm{~mm}$ horizontal for the synthetic samples. Samples were analyzed in a liquid nitrogen cryostat $(77 \mathrm{~K})$ to improve definition of higher-order shells. Several samples were also measured at room temperature. These were found to exhibit the same second-shell EXAFS structure as observed at $77 \mathrm{~K}$, but with smaller amplitudes. The monochromator was calibrated using an yttrium foil. EXAFS spectra were background subtracted, splined and analyzed using SIXPack (23). Backscattering phase and amplitude functions required for fitting of spectra were obtained from FEFF 8 (24).

In-Situ SR-PD. SR-PD data were collected in transmission geometry on a 6-circle Huber diffractometer on SSRL beamline $7-2$, using an energy dispersive Vortex detector placed behind 1 mrad Soller slits. Wet samples were loaded into $0.2 \mathrm{~mm}$ inner diameter quartz capillaries. The incident $\mathrm{X}$-ray beam was set to $16.1 \mathrm{keV}(\lambda=0.77 \AA)$. The diffractometer was calibrated with a $\mathrm{LaB}_{6}$ standard. Data were collected in Q-space of $0.02 \AA^{-1}$ intervals out to $\sim 14.5 \AA^{-1}$ in a mode where equal amount of signal count was collected at each point in the diffraction pattern. Multiple scans were added together in order to improve signal-to-noise ratio. The signal at every point in the added scan was more than several tens of thousands counts, and hence, the statistical error in the data was less than $1 \%$. A diffraction pattern for the capillary and water were also taken under similar conditions and then subtracted from the added scans to give data for Pawley refinements. Refinements were done in Topas Academic (25). A multiterm Chebyshev polynomial background function was subtracted from the data. The instrumental parameters and the instrumental peak shape and broadening were modeled on the $\mathrm{LaB}_{6}$ data and kept fixed. For the rest of the samples a Pawley fit of the data set was undertaken and lattice parameter, 2theta zero and crystallite size (based on Lorentian broadening of the peaks) were refined.

\section{Results and Discussion}

Transmission Electron Microscopy (TEM). TEM and HRTEM micrographs of the reduced uranium product are given in Figure 1. The ring electron diffraction pattern (Figure 1b) obtained from a particle aggregate (Figure la) was indexed for the $\mathrm{UO}_{2}$ cubic unit cell. The HRTEM images in Figures $1 \mathrm{c}$ and $1 \mathrm{~d}$ (original and Fourier filtered) demonstrate the typical size of individual particles to range from 1.5 to 3.5 $\mathrm{nm}$, and the highest frequency particle diameter occurs at ca2.5 nm (Figure 1e). This is consistent with previous studies $(15,16,26-29)$. The size of particles was the same for all samples, independent of the $\mathrm{pH}$ of production and postformation treatment.

X-ray Absorption Near Edge Spectroscopy (XANES) and X-ray Photoelectron Spectroscopy (XPS). Linear combination fitting of XANES spectra with model compounds of U(VI) and U(IV) indicated that the remaining U(VI) content was below the detection limit of this technique $(\sim 5$ to $10 \%$ of total U) (see SI). This technique may not be sensitive to small concentrations of $U(V)$, if present. XPS shows the presence of up to $13 \%$ oxidized U (see SI). This discrepancy could be due to (a) minor oxidation of the samples during the several months of time that elapsed after XANES and prior to XPS measurements and (b) the presence of some oxidized $U$ (i.e., $5-10 \%$ ) in the samples during XANES acquisition.

Structural Analysis. U L LII-edge EXAFS spectroscopy was used to characterize the short-range (i.e., $<4 \AA$ ) and intermediate-range (i.e., ca. $4-10 \AA$ ) structure of the uraninite products obtained following microbial $\mathrm{U}(\mathrm{VI})$ reduction. SR$\mathrm{PD}$ was used to characterize the long-range structure, i.e., the unit-cell dimension and particle size.

EXAFS: Short and Intermediate -range structure. EXAFS and the associated Fourier transforms (FT) of biogenic uraninite formed at $\mathrm{pH} 8$ with no subsequent cleaning treatment (Table 1 Sample A) are compared to spectra for abiotic $\mathrm{UO}_{2.00}, \mathrm{UO}_{2.05}$ and $\mathrm{UO}_{2.25}$, in Figure $2 \mathrm{a}$ and $\mathrm{b}$, respectively. Qualitative comparison of the spectra leads to several important conclusions: (a) The correspondence between the biogenic uraninite and stoichiometric $\mathrm{UO}_{2.00}$ is very good. In particular, all of the FT peaks observed for $\mathrm{UO}_{2.00}$ are present in the biogenic uraninite sample up to $c a$ $8 \AA, R+\delta R$. Beyond this point no FT peaks are present in the biogenic uraninite FT. This result indicates that the overall $\mathrm{UO}_{2}$ structure is qualitatively well preserved over a length of $\sim 1 \mathrm{~nm}$, and we infer that the ordered portion is located in the particle core. It is reasonable to expect the particles to have overall pseudospherical symmetry due to their pseudospherical shape, cubic unit cell symmetry, and small size. Consequently, if the core is not ordered, then it would follow 

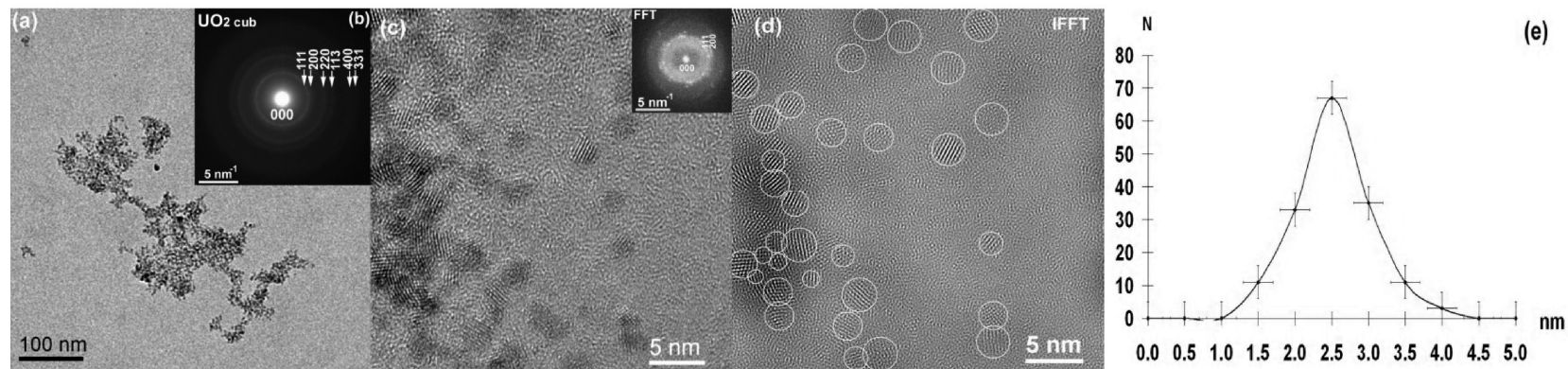

FIGURE 1. (a) TEM micrograph and (b) SAED pattern of biogenic uraninite formed at pH 6.3 (Sample D in Table 1) with no cleaning treatment, (c) $\mathrm{HRTEM}$ image of $\mathrm{UO}_{2}$ particles with the corresponding diffractogram (FFT), (d) selection of $\mathrm{UO}_{2}$ particles in Fourier filtered HRTEM (IFFT) image for size determination, (e) Histogram of the particle size distribution.
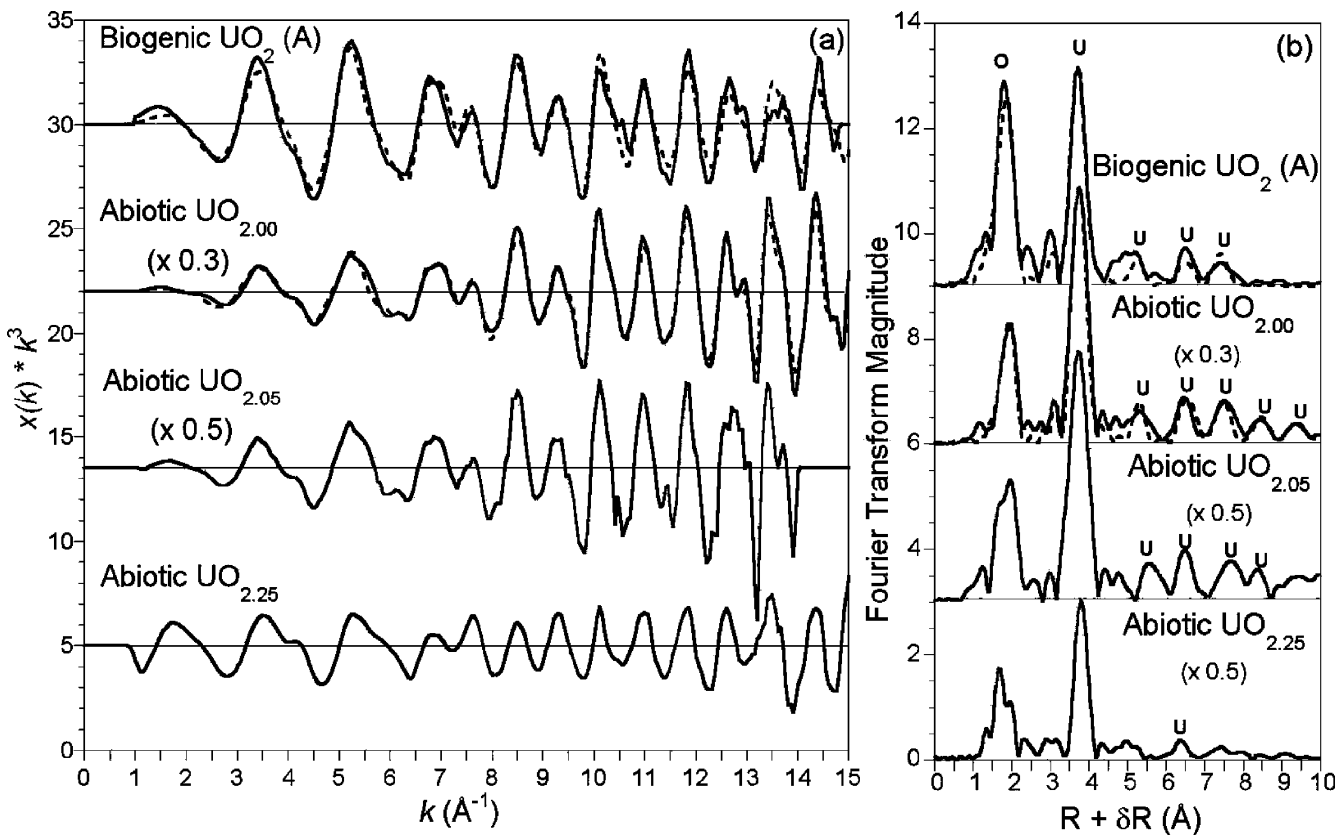

FIGURE 2. (a) EXAFS spectra (solid lines) collected at $77 \mathrm{~K}$ with fit to data (dashed lines) and (b) corresponding Fourier transform for biogenic uraninite formed at $\mathrm{pH} 8$ (Sample $\mathrm{A}$ in Table 1) with no post formation cleaning, abiotic $\mathrm{UO}_{2.00}, \mathrm{UO}_{2.05}$ and $\mathrm{UO}_{2.25}$. $\mathrm{Data}$ are scaled as indicated.

that the ordered portion must reside in an outer region. Such a scenario would invoke two interfaces per particle, one at the oxide-water interface and another at the boundary to the strained core region, an energetically expensive and unlikely arrangement. (b) The ratio of the amplitude of the FT peak of the first $\mathrm{U}-\mathrm{U}$ shell to the first $\mathrm{U}-\mathrm{O}$ shell is reduced for biogenic uraninite in relation to $\mathrm{UO}_{2.00}$, indicating a smaller coordination number of the $\mathrm{U}-\mathrm{U}$ shell, consistent with its nanoparticulate size. (c) The spectrum for biogenic uraninite is different from those of $\mathrm{UO}_{2.05}$ (see below) and $\mathrm{UO}_{2.25}$. The latter two spectra span the range of likely environmental $\mathrm{UO}_{2+x}$ compositions and show the distortions to local- and intermediate-range structure that are characteristic of hyperstoichiometric composition. In particular, the U-O FT peak (Figure 2b) is split into two subshells at ca 2.25 and 2.40 $\AA(30,31)$, subtly so for $\mathrm{UO}_{2.05}$ and strongly so for $\mathrm{UO}_{2.25}$. Local structural distortion destroys much of the FT structure beyond $4 \AA R+\delta R$ in $\mathrm{UO}_{2.25}$, although the unit cell is maintained owing to the preserved order of the $U$ sublattice $(30,31)$. In contrast, the $\mathrm{U}-\mathrm{O}$ shell in biogenic uraninite is not visibly split, and thus, it can be concluded that the structure of biogenic uraninite is qualitatively more similar to stoichiometric $\mathrm{UO}_{2.00}$ than to $\mathrm{UO}_{2+x}$. The presence of small quantities of U(VI), as suggested by XPS, can not be ruled out from structural arguments, and it is thus possible that the samples may have exhibited small values of $x$.
An EXAFS fitting model was developed for the structure of abiotic $\mathrm{UO}_{2.00}$ and is described in the SI. Based on the qualitative structural analogy between biogenic uraninite and stoichiometric $\mathrm{UO}_{2.00}$, the stoichiometric $\mathrm{UO}_{2}$ EXAFS model was applied to the sample spectra, after being modified to account for (1) the fact that $\mathrm{ca} 50 \%$ of the atoms in a $3 \mathrm{~nm}$ nanoparticle are at or near the surface and therefore lack part of their bulk second-shell coordination environment and (2) the presence of an ordered core region (10). To account for the former effect, $\mathrm{CN}$ values for the first $\mathrm{U}-\mathrm{U}$ shell were allowed to float. To account for the latter, a model was developed to quantify the extent of the ordered region of the nanoparticles. The methodology for this approach is given in the SI. This approach allows a single fit parameter to be floated in lieu of separate CNs for $\mathrm{U}-\mathrm{U}$ shells with $R$ $>4 \AA$. This single fit parameter, named here as the EXAFS structural coherence length (SCL), provides a measure of the distance over which the structural order is preserved in the particles, as detected by EXAFS. The $3.86 \AA \mathrm{U}-\mathrm{U}$ shell was not used to constrain the SCL in acknowledgment of the fact that short-range $(R<4 \AA)$ order may not reflect intermediate and long-range order. For example, the $3.86 \AA \mathrm{U}-\mathrm{U}$ shell is likely to be contracted at the oxide-water interface.

The $\mathrm{U}-\mathrm{O}$ shell distance for $\mathrm{pH} 8$ uncleaned biogenic uraninite is similar to that of $\mathrm{UO}_{2.00}$ (Tab. 2). Fits using a split oxygen shell to test for the presence of hyperstoichiometric 
TABLE 2. EXAFS Fit Results for Abiotic $\mathrm{UO}_{2.00}$ and Biogenic Uraninite with Varying pH Syntheses and Cleaning Treatment

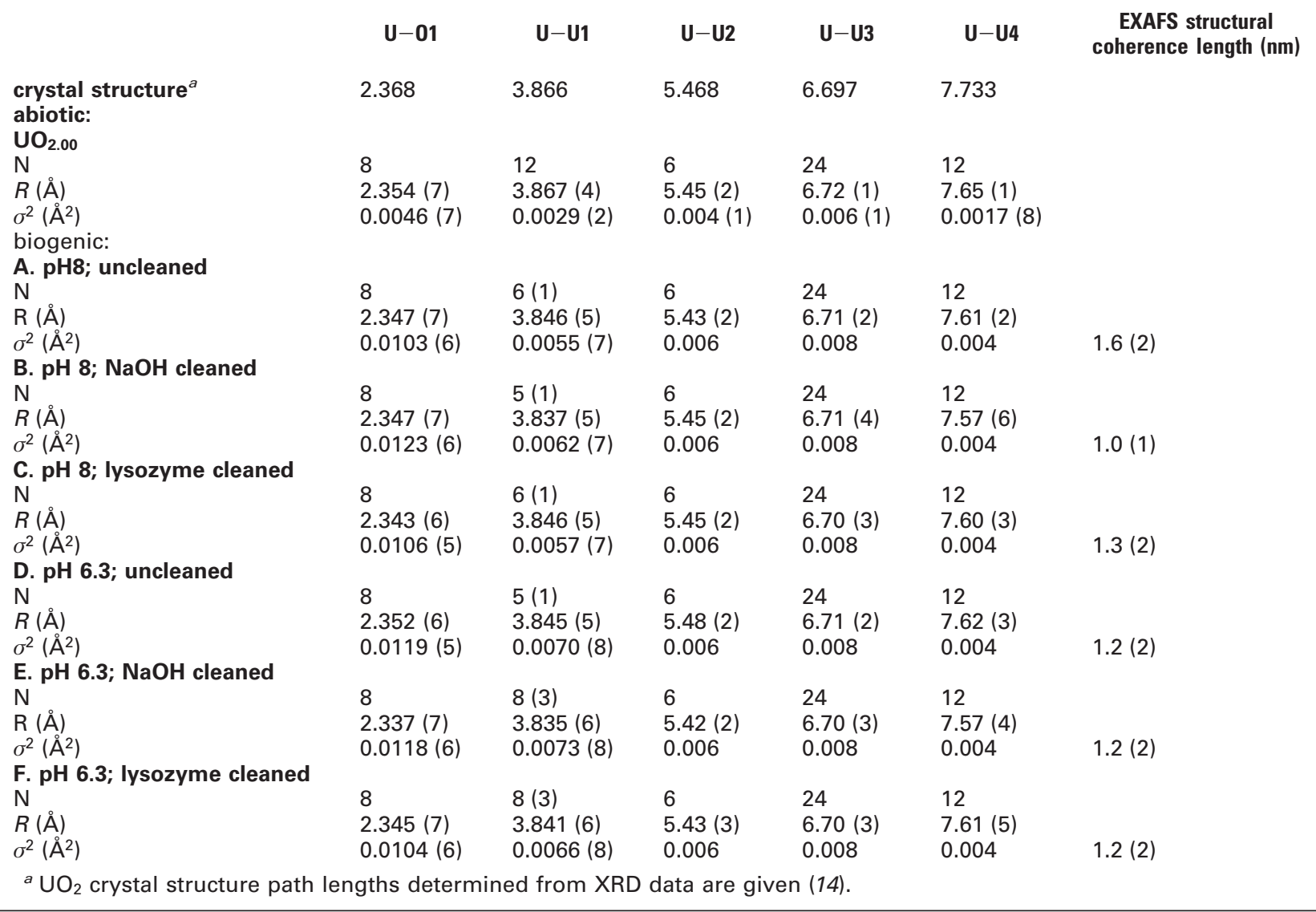

$\mathrm{U}$ sites were attempted, but were not stable and collapsed into a single shell. Similarly, the $\mathrm{CN}$ of $\mathrm{O}$ shells at distances of $<1.9 \AA$, added to test for uranyl cations, went to zero during the optimization. There was no evidence for noncrystalline U-phosphoryl complexes reported previously (15). Thus, we conclude that nanobiogenic uraninite is structurally homologous to stoichiometric $\mathrm{UO}_{2.00}$. The SCL parameter suggests the ordered core region has a diameter of $\sim 1.6 \mathrm{~nm}$. Contraction of the first $\mathrm{U}-\mathrm{U}$ shell relative to the bulk can be explained if the outermost layer of the particle, which contains $50 \%$ of $U$ is affected by the oxide-water interface.

The EXAFS spectra and FTs of biogenic uraninite prepared at $\mathrm{pH} 6.3$ and 8 with varying post formation cleaning treatments are shown in Figures $3 a$ and $b$, respectively. EXAFS derived $\mathrm{U}-\mathrm{O}$ distances are comparable to those of abiotic $\mathrm{UO}_{2.00}$ as shown in Table 2. All $\mathrm{U}-\mathrm{U}$ shells at $<4 \AA$ are contracted as compared to bulk $\mathrm{UO}_{2}$, whereas no systematic contraction is observed for the $\mathrm{U}-\mathrm{U}$ shells $>4 \AA$. This suggests that the cores of the particles are well ordered, exhibit structural homology to abiotic $\mathrm{UO}_{2.00}$ and are unstrained. Again, the distinguishing feature of the biogenic samples is the reduction in the amplitude of the $\mathrm{U}-\mathrm{U}$ shells, as expected for their nanoparticulate size compared to the bulk abiotic $\mathrm{UO}_{2.00}(100-200 \mathrm{~nm}$ diameter particles). Cleaning treatments are seen to diminish the ordered core size for the $\mathrm{pH} 8$ sample series. This trend is not observed for the samples prepared at $\mathrm{pH}$ 6.3.

In-Situ SR-PD: Long-Range Structure. SR-PD results are shown in Figure 4 for $\mathrm{pH} 8$ and $\mathrm{pH}$ 6.3, $\mathrm{NaOH}$ - and lysozymetreated biogenic uraninite (SR-PD data from uncleaned samples were not adequate for Rietveld analysis). Rietveld fits show that the lattice constants for lysozyme-cleaned biogenic uraninite, 5.467 and $5.460 \mathrm{~nm} \mathrm{(pH} 8$ and 6.3, respectively) are comparable to that of abiotic $\mathrm{UO}_{2.00}$ (literature value of $5.4682 \mathrm{~nm}$ and measured value of 5.4647 $\mathrm{nm}$ as shown in Table 3), and therefore, we conclude the lattices are unstrained. As uncleaned biogenic uraninite exhibits at least as much intermediate-range structural order as lysozyme-cleaned, it is reasonable to infer that fresh uncleaned biogenic uraninite is also unstrained. These lattice constants are significantly different from that of $\mathrm{UO}_{2.25}(5.440$ $\AA$ (31)), which reinforces the conclusion that biogenic uraninite is stoichiometric. When treated with $1 \mathrm{M} \mathrm{NaOH}$, the lattice constant is seen to drop to $c a 5.440 \AA$. Although the $5.440 \AA$ value is the same as that of $\mathrm{UO}_{2.25}$, the presence of the latter phase is ruled out as the characteristic strong splitting of the $\mathrm{U}-\mathrm{O}$ shell in this phase is not observed (Figure 3 , Table 2). It thus can be concluded that the $\mathrm{NaOH}$-washed $\mathrm{UO}_{2}$ particle interiors are under compression, and by extension, that hydroxylation of the surfaces at high $\mathrm{pH}$ induces tensile surface stresses. Pawley fits to SR-PD peak shapes provide analytical estimates of the average crystal size of ca $3.5 \mathrm{~nm}$ (Table 3), generally consistent with the TEM results (Figure 1).

Structural Model. Key structural observations can be reconciled as follows. EXAFS show the particle interiors to be highly ordered, with an average diameter $\sim 1.3 \mathrm{~nm}$ (Table 2). Since the overall particle size is $\sim 2.5 \mathrm{~nm}$, it follows that the outer region of the particles must have a thickness of $c a$ $\sim 0.6 \mathrm{~nm}$ (Figure 5). Contraction of the $U-U$ shells at $<4 \AA$ (Table 2) can be accounted for if the surfaces are structurally modified. SR-PD patterns indicate that the unit cell is uncontracted in the absence of $\mathrm{NaOH}$ treatment. Particle sizes determined from SR-PD are consistent with TEM, implying that diffraction occurs from essentially the entire particle, save perhaps the surface region. This observation indicates that the $U$ sublattice is preserved in the biogenic samples, and that structural distortion is local, mostly 

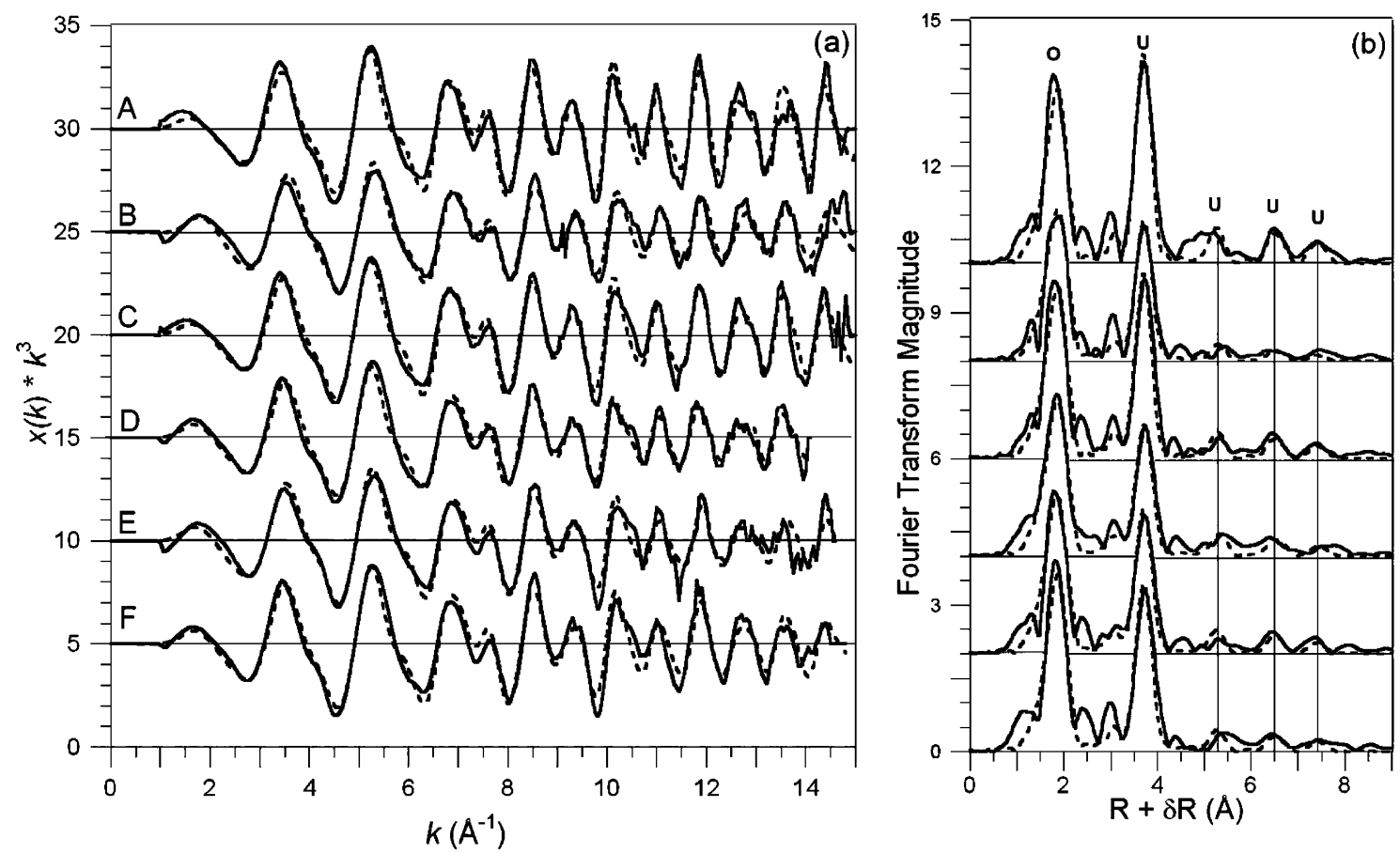

FIGURE 3. (a) EXAFS spectra (solid line) collected at $77 \mathrm{~K}$ with fit to data (dashed line) and (b) corresponding Fourier transforms for biogenic uraninite with varying $\mathrm{pH}$ syntheses and cleaning treatment.

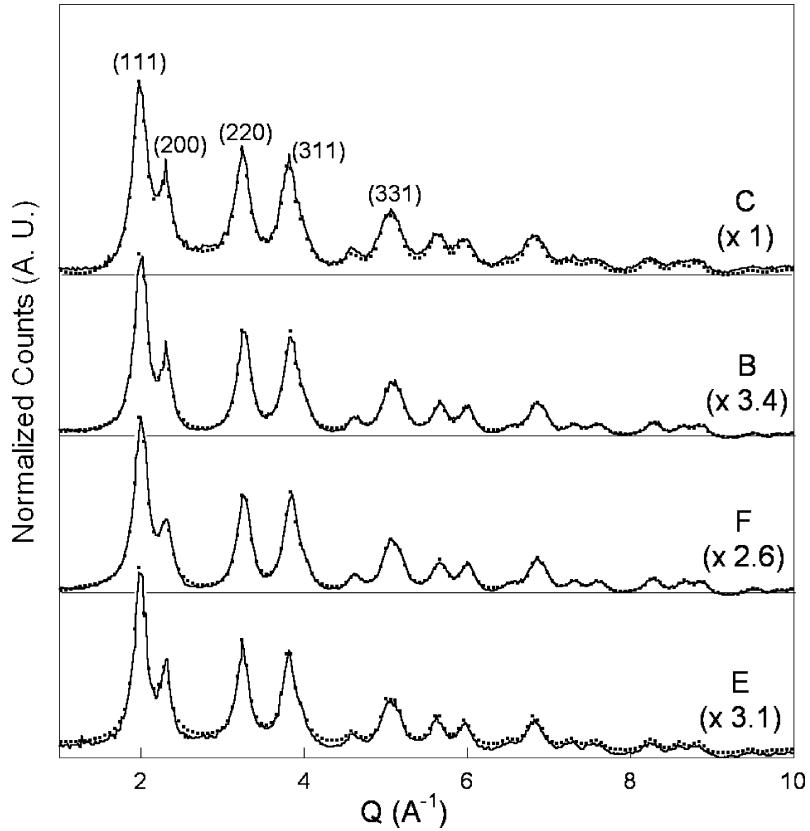

FIGURE 4. In-situ synchrotron powder-diffraction data (solid line) and Pawley refinements (dashed line) of biogenic uraninite with varying $\mathrm{pH}$ syntheses and cleaning treatment (data is scaled as indicated).

occurring in the periphery of the particle. $\mathrm{NaOH}$ cleaning leads to contraction of the unit cell, and at $\mathrm{pH} 8$, to a modest reduction of the intermediate-range structural order, but does not otherwise modify the structural model.

Implications for Subsurface Reactivity. The excess free energy associated with nanoparticulate surfaces, which can affect their structure and stability, can be lowered by relaxation and displacement of surface atoms away from their "bulk" sites. Such rearrangements can create compressive or tensile surface stress that can drive interior expansion or contraction and elevate the Gibbs energy of the solid. Surface free energy that is not compensated for by structural
TABLE 3. Pawley Refinement Fit Results of in-Situ Synchrotron Powder-Diffraction Data of Abiotic $\mathrm{UO}_{2.00}$ and Biogenic Uraninite with Varying pH Syntheses and Cleaning Treatment

$$
\begin{array}{cc}
\text { lattice parameter } & \text { crystal size } \\
(\AA) & (\mathrm{nm})
\end{array}
$$

abiotic $\mathrm{UO}_{2.00}$

literature ${ }^{a}$

$\begin{array}{ll}5.4682 & \\ 5.4647(1) & \\ & \\ 5.467(4) & 3.25(6) \\ 5.460(3) & 3.65(5) \\ 5.444(3) & 3.52(5) \\ 5.430(2) & 3.52(5)\end{array}$

as measured

biogenic $\mathrm{UO}_{2}$

C. $\mathrm{pH}$ 8; lysozyme cleaned

F. pH 6.3; lysozyme cleaned

B. $\mathrm{pH} 8 ; \mathrm{NaOH}$ cleaned

E. $\mathrm{pH}$ 6.3; $\mathrm{NaOH}$ cleaned

$5.444(3)$

$3.52(5)$

${ }^{a}$ The XRD determined lattice parameter for uraninite is given (14).

relaxation also adds to the total free energy of the solid $(32,33)$. In the case of biogenic uraninite, it had been previously estimated that compressive strain of the interior could increase solubility by up to 9 orders of magnitude (10), which would render biogenic uraninite a relatively poor sink phase even under reducing conditions. In contrast, in this study, SR-PD data indicated no strain of the $\mathrm{UO}_{2}$ lattice (i.e., in the uncleaned and lysozyme-cleaned biogenic uraninite). This observation indicates that surface contraction by the first $\mathrm{U}-\mathrm{U}$ shell (at $<4 \AA$ ) does not drive strain of the particle interiors, and thus, does not necessarily translate into strong implications for solubility.

The stoichiometry of biogenic uraninite is likely to be an important moderator of structure and stability (11-13), but has received little attention in the environmental remediation literature. Hyperstoichiometic compositions $\left(\mathrm{UO}_{2+x}, 0<x \leq\right.$ $0.25)$, rather than stoichiometric $\mathrm{UO}_{2.00}$ are expected in natural sedimentary uraninites (13). In contrast, this study shows that biogenic nano-uraninite is structurally homologous to stoichiometric $\mathrm{UO}_{2.00}$. This observation could be due to the biological mechanism of reduction, in which high U(IV) concentrations are found near enzyme sites, leaving little opportunity for the incorporation of $U(V I)$. In addition, the 


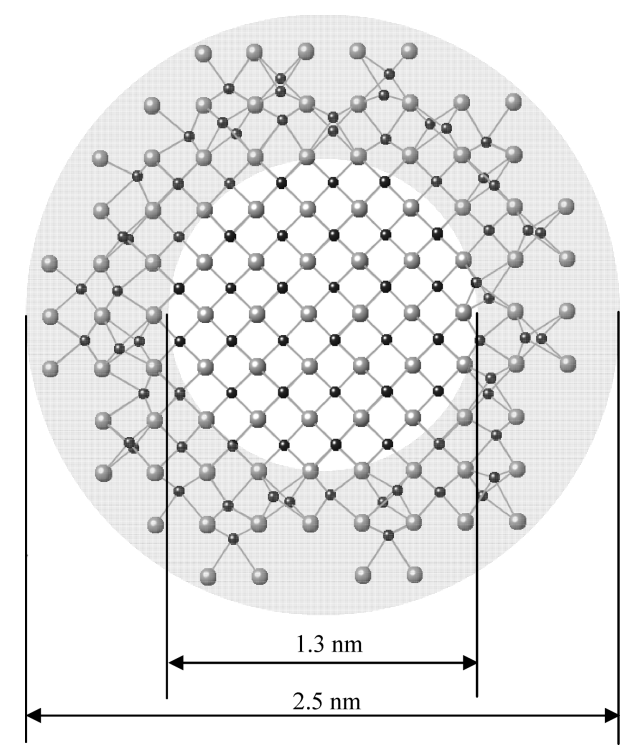

FIGURE 5. Structural model of nanobiogenic uraninite (Black = 0 ; Grey $=\mathrm{U}$ ). Note: Atom displacements in periphery are exaggerated to emphasize the structure.

formation of hyperstoichiometry beyond $x=0.07$ may not be supported at room temperature (34). Lastly, it has been proposed that hyperstoichiometry in bulk $\mathrm{UO}_{2}$ arises through the presence of structural $\mathrm{U}(\mathrm{VI})$ within $\mathrm{UO}_{2}(13)$ and this $\mathrm{U}(\mathrm{VI})$ impurity may be exsolved as a segregated nanoscale $\mathrm{U}(\mathrm{VI})$ phase (31). Such behavior may not be possible in nanoparticles because they are too small to support phase segregation.

The absence of internal strain and apparent nearstoichiometric composition suggests that thermodynamic constants for $\mathrm{UO}_{2}$ may provide an appropriate starting point for modeling biogenic uraninite. The similarity of biogenic uraninite solubility to that of $\mathrm{UO}_{2}$ corroborates this conclusion (35). Uraninites formed in the field are likely to contain structural impurities, including $\mathrm{U}(\mathrm{VI})$, and to be partially corroded (11-13), which is expected to increase the stability of uraninite relative to $\mathrm{UO}_{2}$. Ongoing and future work will consider these aspects and link them to expected properties of biogenic uraninite in the subsurface.

\section{Acknowledgments}

We thank Dan Schwarz for preparing the synthetic $\mathrm{UO}_{2}$ used in this study. We thank Carol Morris, Ray Russ, and Darryl Murray for radiation control technical support and Joe Rogers, Jeff Maske, and Ron Marks for their assistance with beam line hardware and data acquisition systems. Funding for this project was provided by DoE-OBER SLAC project number SCW0041 and grant no. DE-FG02-06ER64227 to EPFL. Portions of this project were supported by the SSRL Environmental Remediation Science Program. Portions of this research were carried out at the Stanford Synchrotron Radiation Laboratory, a national user facility operated by Stanford University on behalf of the U.S. DoE, OBES. The SSRL Structural Molecular Biology Program is supported by the Department of Energy, Office of Biological and Environmental Research, and by the National Institutes of Health, National Center for Research Resources, Biomedical Technology Program. Work carried out at EPFL was also funded by the Swiss NSF grant no. 20021-113784. Work carried out at LANL was funded by the Heavy Element Chemistry program of DoE OBES under contract W-7450. We thank Al Miller for guidance in using the Scienta ESCA-300 at Lehigh University. We thank three anonymous reviewers for their helpful comments. Safety: This work involved the handling of Uranium-238 and the development of standard handling protocols.

\section{Supporting Information Available}

Detailed description of sample production, additional material characterization and modeling approach (including 4 figures and 2 tables). This material is available free of charge via the Internet at http://pubs.acs.org.

\section{Literature Cited}

(1) Riley, R. G.; Zachara, J. M.; Wober, F. J., Chemical Contaminants on DOE Lands and Selection of Contaminant Mixtures for Subsurface Science Research. DOE/ER-0547T; DOE Office of Energy Research: Washington, DC, 1992; p 77.

(2) Zachara, J. M.; Brown, C.; Christensen, J.; Davis, J. A.; Dresel, E.; Liu, C.; Kelly, S.; McKinley, J.; Serne, J.; Um, W., A Site-Wide Perspective on Uranium Geochemistry at the Hanford Site., PNNL Report 17031; Pacific Northwest National Laboratory: Richland, WA, 2007; p 224.

(3) DOE. Bioremediation of Metals and Radionuclides. . What It Is and How It Works, LBL 42595; Lawrence Berkeley National Laboratory: Berkeley, CA, 2003.

(4) Anderson, R. T.; Vrionis, H. A.; Ortiz-Bernad, I.; Resch, C. T.; Long, P. E.; Dayvault, R.; Karp, K.; Marutzky, S.; Metzler, R. D.; Peacock, A.; White, D. C.; Lowe, M.; Lovely, D. R. Stimulating the in-situ activity of Geobacter species to remove uranium from the groundwater of a uranium-contaminated aquifer. Appl. Environ. Microb. 2003, 69, 5884-5891.

(5) Istok, J.; Senko, J. M.; Krumholz, L. R.; Watson, D.; Bogle, M. A.; Peacock, A.; Chang, Y.-J.; White, D. C. In situ bioreduction of technetium and uranium in a nitrate-contaminated aquifer. Environ. Sci. Technol. 2004, 38, 468-475.

(6) Senko, J. M.; Istok, J. D.; Suflita, J. M.; Krumholz, L. R. In-situ evidence for uranium immobilization and remobilization. Environ. Sci. Technol. 2002, 36, 1491-1496.

(7) Wu, W.-M.; Carley, J.; Fienen, M.; Mehlhorn, T.; Lowe, K.; Nyman, J.; Luo, J.; Gentile, M.; Rajan, R.; Wagner, D.; Hickey, R.; Gu, B.; Watson, D. B.; Cirpka, O.; Kitanidis, P.; Jardine, P. M.; Criddle, C. Pilot-scale in situ bioremediation of uranium in a highly contaminated aquifer. I. Conditioning of a treatment zone. Environ. Sci. Technol. 2006, 40, 3978-3985.

(8) Wu, W.-M.; Carley, J.; Gentry, T.; Ginder-Vogel, M.; Fienen, M.; Mehlhorn, T.; Yan, H.; Caroll, S.; Pace, M.; Nyman, J.; Luo, J.; Gentile, M.; Fields, M. W.; Hickey, R.; Watson, D. B.; Cirpka, O.; Zhou, J.; Fendorf, S.; Kitanidis, P.; Jardine, P. M.; Criddle, C. Pilot-scale in situ bioremediation of uranium in a highly contaminated aquifer. 2. Geochemical control of U(VI) bioavailability and evidence of U(VI) reduction. Environ. Sci. Technol. 2006, 40, 3986-3995.

(9) Yabusaki, S. B.; Fang, Y.; Long, P. E.; Resch, C. T.; Peacock, A. D.; Komlos, J.; Jaffe, P. R.; Morrison, S. J.; Dayvault, R. D.; White, D. C.; Anderson, R. T. Uranium removal from groundwater via in situ biostimulation: Field-scale modeling of transport and biogological processes. J. Contam. Hydrol. 2007, 93, 216-235.

(10) Suzuki, Y.; Kelly, S. D.; Kemner, K. M.; Banfield, J. F. Nanometresize products of uranium bioreduction. Nature 2002, 419, 134135.

(11) Finch, R. J.; Ewing, R. C. The corrosion of uraninite under oxidizing conditions. J. Nucl. Mater. 1992, 190, 133-156.

(12) Janeczek, J.; Ewing, R. C. Dissolution and alteration of uraninite under reducing conditions. J. Nucl. Mater. 1992, 190, 157-173.

(13) Janeczek, J.; Ewing, R. C. Structural formula of uraninite. J. Nucl. Mater. 1992, 190, 128-132.

(14) Wyckoff, R. W. G., Crystal Structures; John Wiley \& Sons: New York, 1978; Vol. 2.

(15) Senko, J. M.; Kelly, S. D.; Dohnalkova, A. C.; McDonough, J. T.; Kemner, K. M.; Burgos, W. D. The effect of U(VI) bioreduction kinetics on subsequent reoxidation of biogenic U(IV). Geochim. Cosmochim. Acta 2007, 71, 4644-4654.

(16) Singer, D. M.; Farges, F. ; Brown, G. E., Jr. , Biogenic $\mathrm{UO}_{2}$ -characterization and surface reactivity. In X-Ray Absorption Fine Structure - XAFS13. AIP Conference Proceedings; Hedman, B., Pianetta, P. , Eds.; American Institute of Physics: Stanford, CA, 2006; Vol. 882, pp 277-279.

(17) Komlos, J.; Mishra, B.; Lanzirotti, A.; Myneni, S.; Jaffe, P. Realtime speciation of uranium during active bioremediation and U(IV) reoxidation. J. Environ. Eng. 2008, 134, 78-86. 
(18) Kelly, S.; Kemner, K. M.; Carley, J.; Criddle, C.; Jardine, P. M.; marsh, T. L.; Phillips, D.; Watson, D.; Wu, W.-M. Speciation of uranium in sediments before and after in-situ biostimulation. Environ. Sci. Technol. 2008, 42, 1558.

(19) Bencheikh-Latmani, R.; Middleton Williams, S.; Haucke, L.; Criddle, C. S.; Wu, L.; Zhou, J.; Tebo, B. M. Global transcriptional profiling of Shewanella Oneidensis MR-1 during Cr(VI) and U(VI) reduction. Appl. Environ. Microb. 2005, 71, 7453-7460.

(20) Marshall, M. J.; Beliaev, A. S.; Dohnalkova, A. C.; Kennedy, D. W.; Shi, L.; Wang, Z.; Boyanov, M. I.; Lai, B.; Kemner, K. M.; McLean, J. S.; Reed, S. B.; Culley, D. E.; Bailey, V. L.; Simonson, C. J.; Saffarini, D. A.; Romine, M. F.; Zachara, J. M.; Fredrickson, J. K. c-Type cytochrome-dependent formation of U(IV) nanoparticles by Shewanella oneidensis. PLoS Biology 2006, 4, e268.

(21) Fredrickson, J. K.; Zachara, J. M.; Marshall, M. J.; Beliaev, A. S. Biogeochemical mechanisms controlling reduced radionuclide particle properties and stability. In 2nd Annual DOE-ERSP PI Meeting: Abstracts, LBNL-59453 Abs. 2007; Lawrence Berkeley National Laboratory: Berkeley, CA, 2007; p 44.

(22) Stadelmann, P. http://cimewww.epfl.ch/people/stadelmann/ jemswebsite/jems.html.

(23) Webb, S. M. SIXPack: a graphical user interface for XAS analysis using IFEFFIT. Phys. Scr. 2005, T115, 1011-1014.

(24) Ankudinov, A. L.; Ravel, B. L.; Rehr, J. J.; Conradson, S. D. Real space multiple scattering calculations of XANES. Phys. Rev. B. 1998, 58, 7565 .

(25) Coelho, A. A. TOPAS-Academic. http://members.optusnet.com.au/ $\sim$ alancoelho.

(26) Beyenal, H.; Sani, R. K.; Peyton, B. M.; Dohnalkova, A. C.; Amonette, J. E.; Lewandowski, Z. Uranium immobilization by sulfate-reducing biofilms. Environ. Sci. Technol. 2004, 38, 20672074.

(27) Schofield, E.; Bernier-Latmani, R.; Veeramani, H.; Sharp, J.; Clark, D. L.; Conradon, S. D.; Bargar, J. R. Structural chemistry of cation doped bacteriogenic $\mathrm{UO}_{2}$. Geochim. Cosmochim. Acta 2007, 71, A902-A902.

(28) Fredrickson, J. K.; Zachara, J. M.; Kennedy, D. W.; Duff, M. C.; Gorby, Y. A.; Li, S. M. W.; Krupka, K. M. Reduction of U(VI) in goethite (alpha-FeOOH) suspensions by a dissimilatory metalreducing bacterium. Geochim. Cosmochim. Acta 2000, 64, 30853098.

(29) Lovley, D. R.; Phillips, E. J. P.; Gorby, Y. A.; Landa, E. R. Microbial reduction of uranium. Nature 1991, 350, 413-416.

(30) Allen, G. C.; Tempest, P. A. Ordered defects in the oxides of uranium. Proc. Royal Soc. London, Ser. A. 1986, 406, 325-344.

(31) Conradson, S. D.; Manara, D.; Wastin, F.; Clark, D. L.; Lander, G. H.; Morales, L. A.; Rebizant, J.; Rondinella, V. V. Local structure and charge distribution in the $\mathrm{UO}_{2}-\mathrm{U}_{4} \mathrm{O}_{9}$ system. Inorg. Chem. 2004, 43, 6922-6935.

(32) Banfield, J. F.; Zhang, H., Nanoparticles in the Environment. In Nanoparticles and the Environment. Reviews in Mineralogical and Geochemistry; Banfield, J. F., Navrotsky, A. , Eds.; Mineralogical Society of America: Washington, D.C., 2001; Vol. 44, pp $1-58$.

(33) Gilbert, B.; Banfield, J. F. , Molecular scale processes involving nanoparticulate minerals in biogeochemical systems. In $\mathrm{Mo}$ lecular Geobiology. Reviews in Mineralogy and Geochemistry; Banfield, J. F., Cervini-Silva, J., Nealson, K. H. , Eds.; Mineralogical Society of America: Washington, D.C., 2005; Vol. 59, pp 109156.

(34) Smith, D. K.; Scheetz, B. E.; Anderson, C. A. F.; Smith, K. L. Phase relations in the uranium-oxygen-water system and its significance on the stability of nuclear wate forms. Uranium 1982, 1, 79-110.

(35) Ulrich, K.; Singh, A.; Schofield, E. J.; Bargar, J. R.; Veeramani, H.; Sharp, J. O.; Bernier-Latmani, R.; Giammar, D. E. Dissolution of biogenic and synthetic $\mathrm{UO}_{2}$ under varied reduction conditions. Environ. Sci. Technol. 2008, 42, 5600-5606.

ES800579G 